crania." Mr. B. obtained medical aid, for the first time since the injury, upon the 3rd of July-eight days afterwards.

On July 12th I saw the case in consultation: the patient said that the eye felt distended, and that the eyelids seemed to press upon the globe, although neither spasm of the orbicularis muscle nor chemosis of the conjunctiva were present. In the left temple a sense of pressure was experienced, which descended to the upper wisdom tooth of the same side; and thence pain of a more acute character spread over the corresponding half of the face and head. The scalp was so sore that the slightest touch was insupportable. The pains underwent considerable aggravation at night. Mr. B. had hitherto used linen, dipped from time to time in cold water, as a local application to the painful parts, with the effect of inducing perfect ease so long as the temperature of the surface was maintained at a low degree. Darkness was indispensable for the comfort of the eye, which presented, on examination, intense conjunctival redness, and iritis with watery discharge.

History. Nine years before, the patient met with a similar accident from the gold solution: it was followed by ophthalmia, intolerance of light, and hemicrania, for which he used poultices only, and in a week resumed his avocations. A year and nine months since, he was laid up two months and nine days with acute rheumatism, which affected the head, and the joints both large and small. He got out of doors on the 2nd of December, but was not free from pain. At Christmas the disease again detained him within doors five weeks.

It would be foreign to my object to relate the treatment I recommended for the ophthalmia; it will suffice to say that, in less than three weeks, the eye was healthy functionally and organically, and the patient able to walk several miles.

\section{CASE OF SWALLOWING AN ARTIFICIAL TOOTH, WITH ITS PLATE.}

By Edward Lister, Esq., Liverpool.

On the 22nd October, 1855, I was requested to visit a lady, aged 26 , who had swallowed a mouthful of pancake, and supposed that a portion of it had remained in the throat. The probang was introdnced, and removed the obstruction.

Her husband called upon me the following morning, and said that his wife had been in the habit of wearing a false tooth attached to a gold plate for several years; and that, abcut half an hour after my departure, she had missed it, and felt certain that she must have swallowed it.

Oct. 23rd. She passed a very restless night, and complained of pain on the left side of the epigastrium, which increased upon pressure. I directed her to apply warm fomentations to the part, which in some measure relieved the pain. Her countenance appeared irritable; her bowels were in a confined state. I ordered a half-pint mixture containing sulphate of magnesia, powdered acacia, and tincture of hyoseyamus; and directed her to partake of as much farinaceous food as possible.

7 P. ar. The bowels have been freely moved by the mixture. About 2 o'clock she experienced very great pain, but at the present time it is much better, and has moved somewhat towards the pyloric orifice of the stomach. She was ordered to continue her merlicine in smaller doses. Her appetite is poor; she has not the least desire for food. I requested her to be particular in examining her evacuations.

Oct. 24th, 11 A.sr. She feels much better, and wishes to sit up. The appetite still remains low. The bowels have been moved twice since the last visit.

2 p.x. The pain has increased to a great degree, and is of a twitching character. I ordered her to have twenty-five minims of liquor opii sedativus, and to discontinue her medicine.

Oct. 28th. She still complains of slight pain in the epigastric region, in precisely the same situation as before. I ordered a mixture containing 3 iss of liquor opii sedativus, a fourth part to be taken on any material increase of the pain.

Oct. 31st. She is much the same. The pain is increased at times, but is relieved by the opiate mixture. The bowels were ordered to be regulated, when required, with castor oil.

Nov. 8th. The pain is less severe than before, but remains in the same situation. She does not require the opiate mixture, and the bowels act regularly. The appetite is still poor.

Nov. 23rd. She informs me that she has eaten some roast beef and potatoes on the 12th instant, and from that time she has experienced no pain whatever, and feels quite well.

She examined her motions regularly for the first three weeks, not afterwards; therefore it is impossible to state whether the gold plate has passed since that time. She has procured another plate and tooth of the same shape and size.

\section{DEATH FOLLOWING THE INHALATION OF CHLOROFORM IN SURGICAL OPERATIONS.}

By T. Holmes, Esq., F.R.C.S.

THEne seems to have arisen lately a desire to deprecate the employment of chloroform in surgical operations, and to repre. sent it as dangerous to the patient's life at the moment of administration, and injurious to the after progress of the case. We are told of the frightful frequency of deaths from chloroform; of its exercising some unexplained secondary agency, unfavourable to the healing of wounds; of its predisposing to pyæmia; of a depressing influence attributed to it, analogous to that of copious bleeding. Now, all this is so opposed to what a daily familiarity with the use of chloroform had led me to believe, that I was induced to review my own experience in the matter, and to look at the published records of the anæsthetic treatment, as contained in the British and continental medical journals, in order to test the accuracy of my previously formed opinions. In the course of this search I came across a valuable paper in the Association Journal for 1853 (p. 131, ) containing a tabular view of the deaths from chloroform (the compilers of which are acknowledged to be indebted principally to Dr. Snow,) and some very sensible remarks thereon. It will perhaps be acceptable that I should continue this table down to the end of the past year, and accompany it by some remarks on the method of administering chloroform, which I have seen reason to believe to be the safest, and on the contraindications, if there be any, to the exhibition of the drug.

I may premise that the following table is compiled from a careful search through the volumes of the medical periodicals published at home and abroad; and that I have not wilfully omitted any, except two cases, both of which were extracted from non-medical papers without any guarantee of their authenticity; in one the editor professed his disbelief, and the other was evidently an American hoax. I make this observation in consequence of a statement recently made by a correspondent of the Medical Times to the effect that deaths from chloroform in London hospitals have been concealed of late days. I can only say that I am quite ignorant of any such concealment, and that I should think it hardly possible, considering the publicity under which hospital surgeons practise, and the habit of holding inquests in such cases. I should be loath, however, to believe, on no better evidence than a random assertion, that English surgeons ever contemplated such dishonesty. I think, therefore, I may say that (errors apart) this table contains all the deaths which have so occurred during the administration of chloroform from the end of 1852 where the former list stops, to the end of 1855. That some of them were not the consequence of such administration, I think admits of no doubt. I shall have occasion to remark hereafter on one case of this kind (appended to the Table), which occurred at St. George's Hospital. The same remark applies to No. 41. 'The list shows that the number of deaths from chloroform which have come to light in London and the provinces, as well as abroad, have averaged about six per annum since the introduction of chloroform; that the number is not on the increase of late,* while the use of the drug has been steadily extending ever since its introduction; and that, therefore, we may hope that, so far from its primary administration having become more hazardous, increased practice in its use, and perhaps increased caution in its administration, have still further diminished the little risk which attached to it at first.

In the face of records, showing fifty deaths, most of them occurring under the care of the most experienced surgeons, assisted in many instances by gentlemen whose special duty it is to give chloroform, it would be vain to deny that the administration of this drug is attended with some risk. But is it rational to expect that it should be altogether free from risk? that the power of voluntary motion and sensation should be altogether abolished by the circulation of poisoned blood in the brain without any danger whatever to the motions of respiration and circulation, dependent as they are on the integrity of parts so intimately connected with those which regulate the former functions? Surely not. Nor do the more judicious

I find no deaths from chloroform reported in the Lancet, vol. i, for last year; and do not remember to have heard of any lately, except the case a St. Thomas's Hospital, a short time ago. 
advocates of chloroform claim for it any such unattainable safety. I find indeed that, in its early days, some of those who were directly connected with its invention were inclined to deny that any risk attached to it at all, or that any precautions were necessary in its use. Edinburgh surgeons, however, have now, I fear, been convinced by the same lamentable experience as their London brethren, that the same minute precaution are necessary in handling this as any other powerful remedy; and that, in spite of every such precautions, some accidents wil occasionally occur. Taking this fact for granted, then, does it furnish a valid objection to the use of chloroform? To answer this, we must understand the conditions of the question. If deaths are to go on at the same rate in future as they have done in the past, this would constitute a very important element in the calculation, and would, I think, justify us at once in refusing chloroform in any but the graver operations. It is hardly possible to form any guess at the arithmetical proportion which may exist between the number of deaths and the number of cases in which chloroform has been given; but whatever this may be, would not any reasonable man prefer, or any judicious surgeon select for him, the pain of such an operation as amputation of a finger or toe, to any appreciable chance of instant death? This conclusion seems reasonable yet, on the other hand, its effect would be very disastrous to surgery in the present condition of our practice. So accustomed have patients, especially in private practice, become to the idea of painless operations, that it would be hardly possible to persuade them to submit to what they would regard (and justly) as unnecessary torture; and thus a surgeon who should go upon the principle of refusing chloroform in the minor operations would, in all probability, see most of his cases of this kind go wrong from the patient's refusings treatment.

We must endeavour not to limit the application of the anæsthe tic (except in those cases, which I will presently speak of, where we can substitute another as efficient and less dangerous), but to lay down some clear rules whereby to avoid passing the limit which separates the stage of narcotism, where sensation and motion are abrogated, from that in which the movements of respiration and circulation are affected. Now I think we have sufficient evidence before us to show that this is accomplished, with nearly absolute certainty, by avoiding the sudden introduction of large quantities of the vapour into the blood, and by administering the chloroform only sparingly after narcotism is established. At the hospital where I have attended (St. Georgo's), and at King's College, great attention is paid to the former point; and the gradual introduction and sufficient dilution of the vapour is sought to be ensured by the method proposed by Dr. Snow. The result has been that in the practice of both hospitals there bas been, ever since the introduction of chloroform, only one case in which a fatal result was ever attributed to the direct action of the anæsthetic ;* and in that case, as I firmly believe, erroneously. I have introduced the case into my list (No.45), lest I should appear desirous to sup. press the fact; but I do not believe that the fatal syncope was at all connected with the administration of chloroform, and for the following reasons : that the quantity of chloroform expended (for the greater part of which was merely lost by evaporation) did not amount to more than a few drops; that in the ninety seconds during which the inhaler was applied she breathed very seldom, and very imperfectly, and therefore could have inhaled only a very small quantity of the vapour, extremely diluted as that was in consequence of the valve being open; that no trace of chloroform could be found in the blood, though searched for by a process capable of detecting very minute quantities; that the patient was in that condition of health, and that state of nervous excitement, in which sudden death from fear occasionally happens; and, finally, that the opinions expressed by her medical attendants led the coroner's jury to conclude that the accident was not the result of the adminis-

* In order that no suspicion may rest upon me of wishing to conceal facts which make against chloroform, I will mention liere the few other cases in which it has appeared to produce unfavourable effects. In a patient operated on some years ago for tumour of the upper jaw, and who died under the operation, it was thought by some that chloroform had paralysed the muscles of the glottis, and so allowed of the passage of blood into the air tube. This was, however, not made out to the satisfaction of others who saw the case. In a patient recently operated on for bernia, who was in a state of great collapse at the time, chloroform was thought to have increased that depression. She died in a few hours; but, in the absence of a post mortem examination (which was unfortunately refused), it was impossible to say that the gut was not ulcerated. In two other cases, it produced severe and re peated fainting fits during the remainder of the day. One was a very old and feeble woman : the other had been kept for a long time under its influeuce (in a protracted operation for vesico-vaginal fistula), and was besides very hysterical, which complicated the symptoms. Neither had any further
bad symptoms. tration of chloroform. The objects sought to be attained by the gradual administration of chloroform are, that the vapour may be always diluted to a certain extent with atmospheric air, and that that dilution may be further increased ad libitum, so that the patient begins by breathing air very slightly mixed with chloroform; and as he becomes accustomed to the taste of it the dose is increased, but never beyond a certain known mixture of air and vapour. In this way narcotism is usually produced at least as rapidly as when the handkerchief or sponge is used (I have ascertained, by repeated observations, that two minutes is the average time at which insensibility comes on); and generally without that irritation of the airpassages, and those distressing struggles so common under the latter method. After the patient is fully under the influence of the vapour, it is only necessary to keep up its action by administering it occasionally when the occurrence of reflex movements shows sensation to be returning. We should bear in mind that common sensation is abolished before the faculty of producing these reflex movements ceases; and that, therefore, no deeper narcotism is required than that which keeps the patient just beyond the verge of the latter condition. It is, I believe, an inattention to these two points which has caused almost all the deaths from chloroform.

The history of the cases, as far as it is intelligibly described, is tolerably uniform. Either the chloroform has been administered continuously, notwithstanding the persistence of narcotism showed that a sufficient quantity was already in the blood, or it was given without any precautions on a sponge, handkerchief, or piece of lint; and this latter was in one case (No. 38) covered with oiled silk, as if purposely to prevent the dilution of the vapour! In many instances it will be noticed that a period of struggling and excitement preceded the fatal syncope. I believe that, in most of these cases, had the chloroform been suspended for a few moments, no alarming symptoms would have followed. The ill effects which may result from the inequality of respiration in these cases has been already pointed out by Dr. Snow. Attention is of course paid both to the breathing and the pulse, and the patient is kept, whenever it is possible, without food for four hours before operation. These precautions seem very matter of course and simple; that they are sufficient in all ordinary cases, the daily experience of eight years, I think, justifies me in asserting; and also in claiming for chloroform thus administered as absolute an immunity from danger as the nature of powerful therapeutic agents permits to them.

I may add, with reference to this method of giving chloroform, that the quantity used is a matter of no great consequence, $*$ as, the same surface being always exposed to the same quantity of air in the bottle (which is also maintained at a low temperature), the ratio of the mixture is constant. Another important advantage of our system of administration (which is, however, of course unattainable out of hospital practice,) is that the chloroform is always given by the same person, who thus acquires the same dexterity in this art as constant practice gives in every other branch of the profession. I again repeat that, with all these or any other precautions, I believe a few fatal accidents will happen; but they may, with proper care, be diminished so far as to make the risk in any given case inappreciable. In the graver cases this risk will go for nothing in determining the question about performing an operation of which, most probably, the patient will not hear unless chloroform is given; in slighter operations it will be for the patient and surgeon to determine whether to submit to the trifling pain or the inappreciable danger. But I hold it utterly visionary to talk, as Dr. James Arnott has recently done in the Medical Times and Gazette, of recurring to the old system of the operating theatre. Theorists, whose eyes are blinded by predilections for their own, and antipathies for other men's inventions, may speak coolly of renouncing the use of the "sweet oblivious antidote," which has obliterated the sufferings of thousands, and has substituted placid sleep, or even delightful visions, for what would otherwise have been the extremity of human agony. Those whose practice has been much among such scenes know better; and such proposals are not visited with the reprobation which they would otherwise excite, only because their impracticability secures them from much serious notice.

In a future communication I will endeavour to sum up the information which may be derived (as to contra-indications, etc.,) from the results of these tables.

* There is a limit to this-viz., that the quantity must not be so large as to cover the openings of the air holes into the central tube in the bottle. 
TABLE OF DEATHS UNDER THE INFLUENCE OF CHLOROFORM IN THE YEARS 1853-54-55.

[Continued from the Association Medical Joursal for 1853, p. 131.]

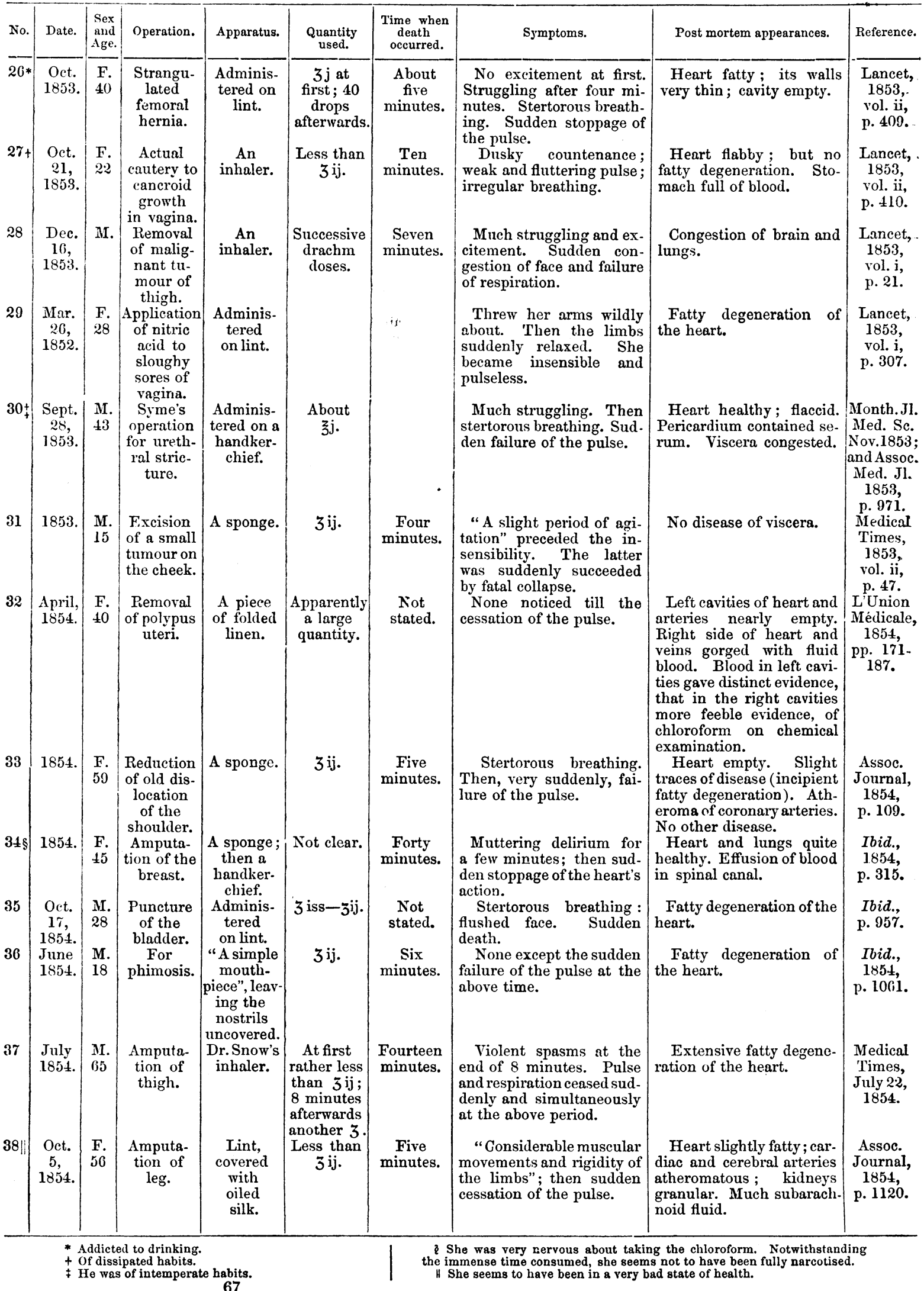




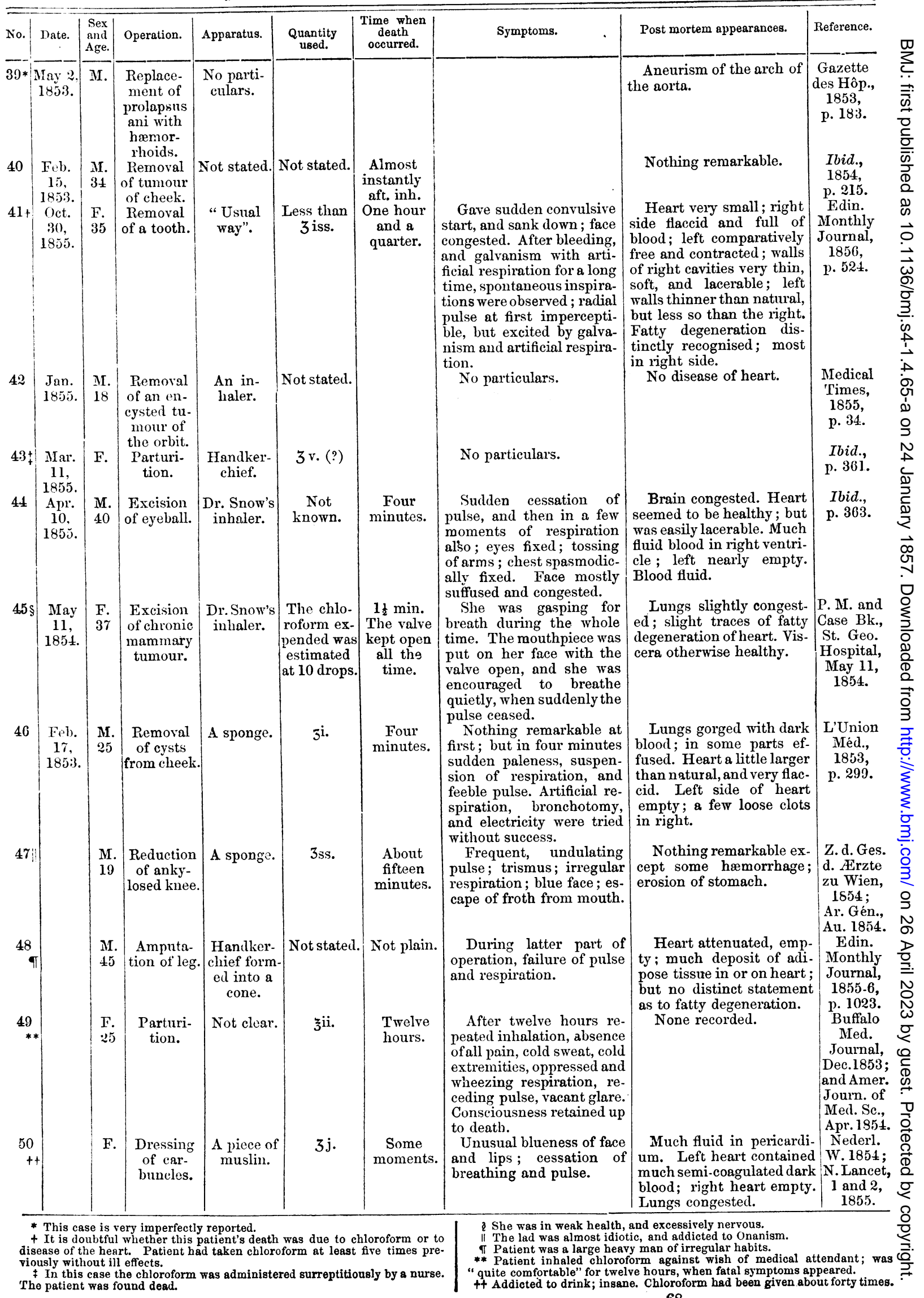

